\title{
STUDI KELAYAKAN BISNIS \\ PENINGKATAN KAPASITAS MESIN PENUNJANG DENGAN KONSEP 7 WASTE LEAN THINKING STUDI KASUS PT. NSBI CILEGON
}

\author{
Hendra Pratama \\ Staff Pengajar Program Studi Teknik Industri, Fakultas Teknik \\ Universitas Muhammadiyah Tangerang \\ Jl. Perintis Kemerdekaan I/33, Cikokol, Kota Tangerang \\ hendra.pratama@outlook.com
}

\begin{abstract}
Abstrak
Studi kelayakan bisnis secara umum menggunakan perhitungan dan teori finansial. Dalam hal ini menjadi kurang meyakinkan bagi pihak manajemen karena banyaknya asumsi dan angka-angka ideal yang diperhitungkan. Karena peningkatan kapasitas mesin penunjang membutuhkan biaya yang tinggi sehingga pihak manajemen mengharapkan adanya studi kelayakan yang menghitung biaya rantai pasok dan produktivitas aktual yang menyeluruh dan komprehensif. 7 Waste in Lean Thinking digunakan untuk mengenali pemborosan dan kendala-kendala pada aliran proses. Hasil yang didapatkan akan dibandingkan dengan hasil perhitungan jika dilakukan peningkatan kapasitas. Pada akhir penelitian dihasilkan jumlah peningkatan produktivitas dan efisiensi kerja dari keseluruhan sistem produksi jika dilakukan peningkatan kapasitas juga perhitungan jangka waktu Titik Impas.
\end{abstract}

Kata kunci: Studi Kelayakan Bisnis, 7 Waste in Lean Thinking, Rantai Pasok, Titik Impas.

\section{PENDAHULUAN}

PT. NSBI Cilegon adalah sebuah perusahaan metal coating untuk lembaran baja yang dibentuk dalam lilitan (steel coil), dengan bahan dasar utama adalah Cold Rolled Coil (CRC) dengan tonase yang umum dipasaran adalah 12 ton hingga 25 ton. Produsen CRC dari luar negeri (CRC import) cenderung bertonase besar antara 18 ton hingga 25 ton.

Persaingan industri baja yang semakin ketat menyebabkan semua pengeluaran biaya sangat diperhitungan, sehingga produsen CRC mengutamakan untuk memproduksi sebanyak mungkin CRC dengan tonase diatas 19T. Hal ini dilakukan produsen CRC dengan pertimbangan biaya rantai pasok yang terdiri dari transportasi, penanganan dan penyimpanan yang cenderung sama dengan CRC kecil, namun secara nilai jual per coilnya sangat berbeda.

Kondisi ini menyebabkan PT. NSBI kesulitan untuk mencari dan memesan CRC yang tonasenya sesuai dengan kapasitas mesin penunjang yaitu Crane, Coil Car dan Pay Of Reel (POR) yang ada, yaitu maksimum 19 ton. Namun peningkatan kapasitas ini sangat tinggi investasinya, sekira USD 900.000.

Berdasarkan perhitungan finansial, investasi tersebut kurang prospektif dalam kondisi bisnis saat ini hingga sekira 2 tahun kedepan. Selain nilai investasi yang tinggi, kepercayaan diri sebagai pelanggan CRC yang cukup besar membuat manajemen merasa bisa meminta pelayanan khusus kepada produsen untuk tetap memproduksi CRC tonase sesuai kebutuhan.

\section{PENGOLAHAN DATA}

CRC merupakan bahan baku utama diproduksi oleh vendor dengan jadwal pengiriman dengan unit trailer per hari sekira 500 ton s.d 2000 ton di hari Senin s.d Jumat per minggu. Setiap unit trailer membawa maksimum $2 \mathrm{CRC}$ dengan tonase total maksimum 40 ton. 

Trailer akan menuju ke area Loading/Unloading bay Warehouse CRC kemudian akan diturunkan dengan menggunakan Crane. Selanjutnya CRC akan ditempatkan di area Storage CRC yang mempunyai kapasitas penyimpanan sebanyak 245 coil atau 4500 ton.

Jika CRC sudah dijadwalkan untuk diproduksi, maka Crane akan mengambil CRC tersebut dan dipindahkan ke area Unpacking untuk dibuka pembungkusnya. Kemudian CRC yang sudah terbuka diangkat lagi dengan Crane menuju area Coil Car untuk kemudian dimasukkan ke POR untuk mulai dijalankan oleh mesin produksi utama.

Pemetaan aliran proses keseluruhan tersebut digambarkan menggunakan model Value Stream Mapping, seperti gambar 1. berikut.

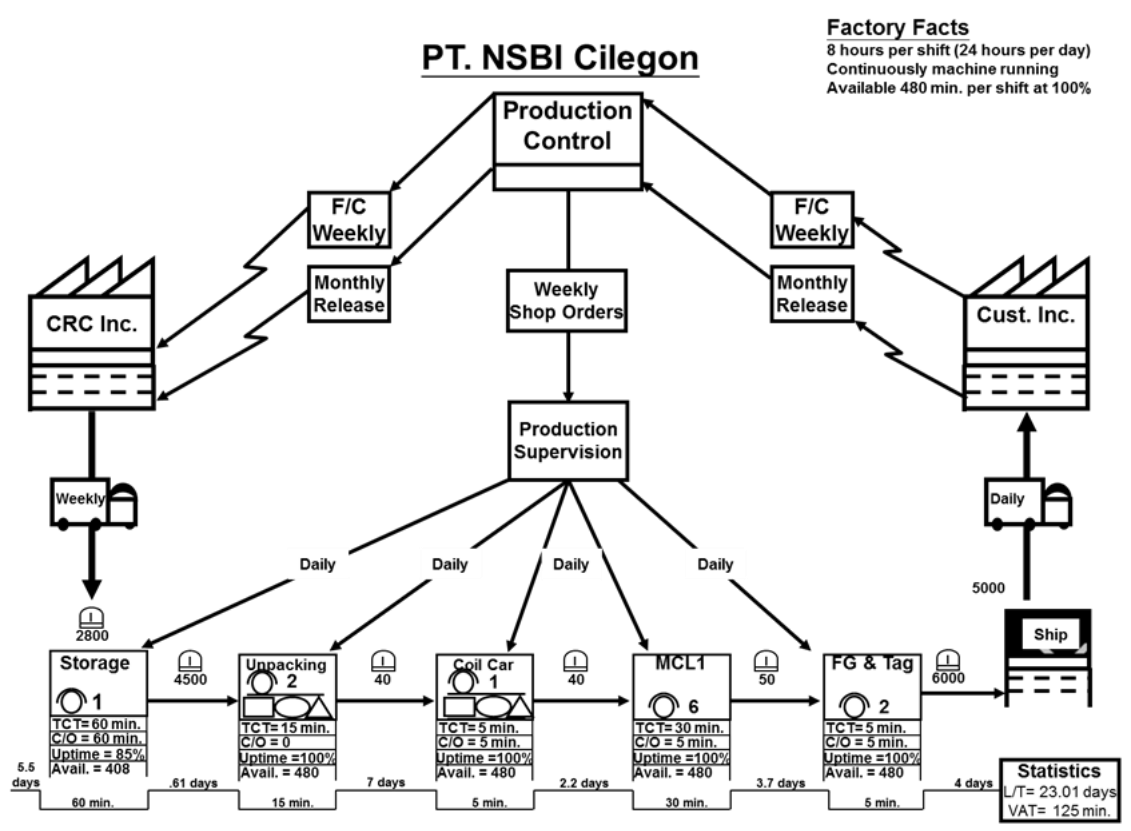

Gambar 1. Peta Aliran Proses Value Stream Mapping.

Dengan kapasitas produksi mesin utama sekira 400 ton per hari maka pengulangan aliran proses bisa mencapai 25 s.d 30 kali. Keseluruhan aliran proses tersebut mempunyai potensi perbaikan dan penghematan yang akan dijadikan salah satu faktor pengaruh keputusan investasi bagi manajemen.

Aliran proses yang menjadi objek penelitian adalah proses bongkar CRC dari unit trailer ke Storage dilanjutkan proses Unpacking hingga penempatan CRC ke Coil Car. Dengan kapasitas tonase saat ini pada mesin penunjang telah menyebabkan adanya kesulitan dalam meningkatkan efisiensi di aliran proses tersebut.

Analisa dilakukan oleh penulis dalam 2 langkah, agar bisa difokusnya kendala, banyaknya pemborosan biaya dan potensi perbaikannya. Langkah analisa tersebut adalah:

\section{Langkah 1. Waste di Rantai Pasok}

Kendala utama yang di identifikasikan untuk diekploitasi sehingga bisa dihitung biaya pemborosan yang timbul adalah dari sisi Supply Chain Management atau manajemen rantai pasok CRC dari import maupun lokal hingga tiba di gudang perusahaan,

Setiap trailer mempunyai kapasitas angkut maksimal 40 ton. Saat ini hanya digunakan maksimum 36 ton dan biaya yang dikeluarkan per unit adalah sekira USD 50. Dengan jumlah pengulangan proses mencapai 35 rit per hari, menghabiskan biaya sekira USD 1.750. dalam sebulan proses suplai CRC adalah 20 hari sehingga total biaya yang dikeluarkan adalah USD 35.000 per bulan.

Area yang dibutuhkan untuk penyimpanan 18 ton CRC sama dengan 20 ton, karena sesuai dengan speksifikasi dari Coil Chock yang ada yaitu maksimum 30 ton per Chock. Sehingga tidak perlu ada perubahan design ataupun tata letak gudang. Namun dikarenakan kemampuan mesin penunjang hanya maksimal 18 Ton, potensi Coil Chock tidak dimanfaatkan optimal. 
Jika tonase CRC yang disimpan adalah minimal 18 ton keatas, maka terjadi peningkatan kapasitas penyimpanan dari 4500 ton menjadi 5000 ton. Ini akan sangat menguntungkan karena CRC import mempunyai siklus kedatangan sekali dalam tiap 2 bulan dan dengan jumlah besar (Bulky) hingga mencapai 2000 ton atau sekira 115 s.d 130 coil CRC. Kondisi saat ini, jika terjadi kekurangan area penyimpanan di gudang perusahaan maka CRC akan ditempatkan sementara di gudang sewa milik pihak ketiga. Biaya sewa gudang per meter persegi adalah USD 5 per bulan yang mampu menyimpan hingga 5 ton. Kontrak sewa gudang adalah per 1 tahun dan luas total minimal adalah 500 meter persegi, maka biaya yang dikeluarkan adalah sekira USD 2.500 perbulan atau USD 30.000 pertahun.

Selain biaya sewa area gudang, biaya penanganan dan transportasi dari pelabuhan menuju gudang sewa dan pengiriman ke gudang perusahaan jika CRC telah diperlukan atau ada area penyimpanan yang kosong, semua ini akan menghabiskan sekira USD 3 per ton. Juga perlu 2 karyawan yang ditugaskan untuk menjaga dan mengatur aktivitas gudang sewa tersebut. Dengan asumsi putaran waktu untuk 1000 ton dalam sebulan, maka biayanya adalah USD 3.000 dengan biaya karyawan USD 300 perbulan.

Kendala yang paling utama ditemukan adalah sulitnya mencari CRC dengan tonase maksimal 18 ton. $\mathrm{CRC}<18$ ton impor sudah sangat minim ketersediaannya dan jika ada harganya sedikit lebih mahal karena biaya penanganan dipelabuhan yang lebih tinggi. Perbedaan biaya total antara CRC dibawah 18 ton dengan minimal 19 ton adalah sekira USD 1 per ton CRC. Dengan kebutuhan 4000 ton perbulan, terjadi pemborosan biaya sekira USD 4.000 perbulan.

\section{Langkah 2. Waste di Operasional}

Kecenderungan produsen memproduksi CRC tonase besar sudah mulai diterapkan oleh produsen lokal, sehingga dalam 6 bulan yang lalu perusahaan telah menghentikan operasi produksi sebanyak 2 kali dengan total selama 10 hari dikarenakan tidak tersedianya CRC. Total kerugian yang dialami perusahaan adalah sekira USD 95.000 dalam 6 bulan atau USD 15.800 perbulan. Besarnya kerugian ini disebabkan perusahaan tetap mengeluarkan biaya gaji karyawan dan kontraktor, gas, listrik, Steam Boiler, sewa gudang dll yang merupakan operational fixed cost serta beberapa variabel cost seperti biaya keluhan pelanggan juga komunikasi dan koordinasi tambahan untuk memastikan kedatangan CRC.

Dengan menganalisa aliran proses dan data CRC 6 bulan (Januari s.d Juni 2016) yang lalu, akan menunjukkan beberapa fakta yang bisa diarahkan kepada potensi penghematan. Data yang diolah menunjukan bahwa sebaran tonase coil dan kuantitinya ditampilkan pada Graphik 1. Terlihat bahwa tonase dengan kuantiti terbanyak adalah di kisaran 14 ton s.d 18 ton.

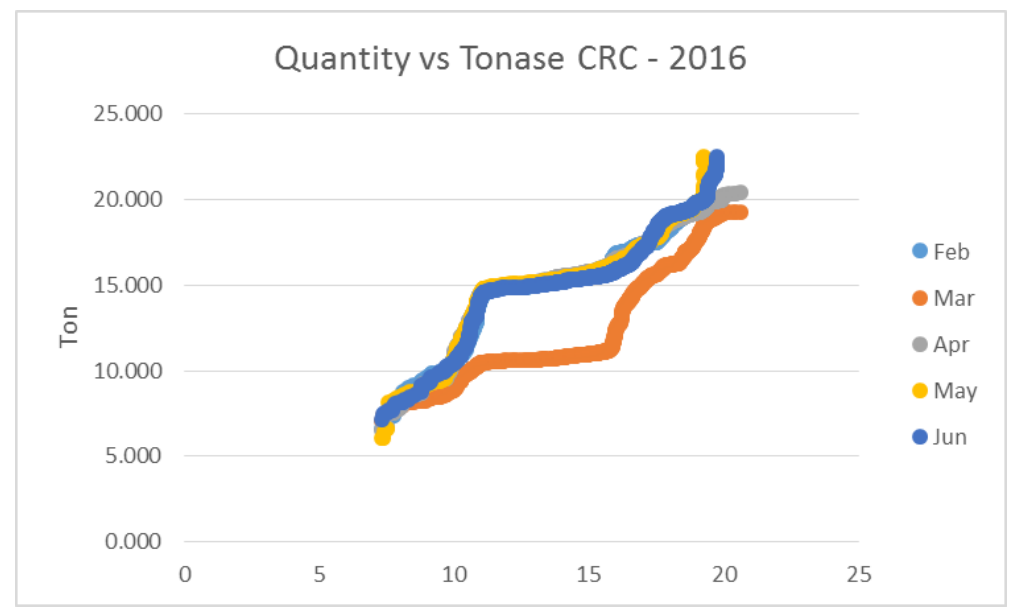

Gambar 2. Grafik Data sebaran tonase coil dan kuantiti

Dari gambar 2. terlihat cukup signifikan jumlah CRC dengan tonase $>18$ ton. Untuk tetap bisa diproses produksi perlu ada beberapa proses manual yang dilakukan oleh operasional. Namun beberapa CRC tetap bisa diproses dengan minimal penanganan khusus.

Tercatat 28 kejadian proses pengurangan tonase CRC agar bisa diproses. Yaitu dengan cara membuang secara manual bahan baku dan dijadikan sampah hingga 1 ton per CRC. Dari proses manual hingga harga CRC yang dibuang, perusahaan mengalami kerugian sekira USD 10.000, termasuk biaya pembuangan limbah. 
Dengan data sebaran tonase coil dan kuantiti, aliran proses serta analisa 7 Waste in Lean Thinking, didapatkan macam pemborosan yang terjadi, sumber penyebab, penanggungjawab atau pihak yang melakukannya, kapan waktu terjadi, alasan yang dianalisa berdasarkan metode 5 mengapa ( 5 Why's) dan diagram tulang ikan (Fishbone Diagram) serta saran perbaikan yang diajukan oleh penulis.

Tabel 1. Tabel Analisa 7 Waste Lean Thinking

\begin{tabular}{|c|c|c|c|c|c|}
\hline Jenis ir|as: & Sumber & $\begin{array}{c}\text { Penanggung } \\
\text { Jawab }\end{array}$ & Waktu Terjadi & $\begin{array}{l}\text { Alasan } \\
\text { Teriadi } \\
\end{array}$ & $\begin{array}{c}\text { Saran } \\
\text { Perbaikan } \\
\end{array}$ \\
\hline Kelebihan Produksi & Suplai CRC & Transporter & \begin{tabular}{|l|}
$\begin{array}{l}\text { Kedatangan } \\
\text { unit trailer }\end{array}$ \\
\end{tabular} & $\begin{array}{l}\text { Minimal } \\
\text { beban trailer }\end{array}$ & $\begin{array}{l}\begin{array}{l}\text { Optimalkan } \\
\text { tonase }\end{array} \\
\end{array}$ \\
\hline Menunggu & $\begin{array}{l}\text { CRC tidak } \\
\text { ada }\end{array}$ & 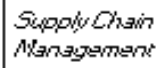 & 10 hari & $\begin{array}{l}\text { Kehabisan } \\
\text { CRC kecil }\end{array}$ & $\begin{array}{l}\text { Atur jadwal } \\
\text { produksi }\end{array}$ \\
\hline \multirow{4}{*}{$\begin{array}{l}\text { Transportasiyang } \\
\text { tidak perlu }\end{array}$} & \multirow{2}{*}{$\begin{array}{l}\text { Pergerakan } \\
\text { unit trailer }\end{array}$} & \multirow[t]{2}{*}{ Transporter } & \begin{tabular}{|l|} 
Kedatangan \\
dan \\
penyimpanan \\
CRC import \\
\end{tabular} & $\begin{array}{l}\text { CRC import } \\
\text { disimpan di } \\
\text { gudang } \\
\text { sewa } \\
\end{array}$ & $\begin{array}{l}\text { Kurangi } \\
\text { import }\end{array}$ \\
\hline & & & $\begin{array}{l}\text { Pengiriman } \\
\text { CRC lokal }\end{array}$ & $\begin{array}{l}\text { Jumlah unit } \\
\text { yang } \\
\text { diperlukan }\end{array}$ & $\begin{array}{l}\text { Optimalkan } \\
\text { tonase CRC }\end{array}$ \\
\hline & \multirow{2}{*}{$\begin{array}{l}\text { Pergerakan } \\
\text { Crane }\end{array}$} & \multirow[t]{2}{*}{ Operator } & \begin{tabular}{|l|} 
Setiap \\
bongkar CRC \\
Setiap \\
pengambilan \\
CRC ke area \\
Lhazoking \\
\end{tabular} & \multirow{2}{*}{$\begin{array}{l}\text { Kesesuaian } \\
\text { iadwal } \\
\text { produksi }\end{array}$} & \multirow{2}{*}{$\begin{array}{l}\text { Optimalkan } \\
\text { tonase CRC }\end{array}$} \\
\hline & & & \begin{tabular}{|l|} 
Setiap \\
pengambilan \\
CRC dari area \\
Lhasoking \\
ke Cod $C$ s. \\
\end{tabular} & & \\
\hline Kelebihan Proses & $\begin{array}{l}\text { Bongkar } \\
\text { pembungkus }\end{array}$ & Operator & $\begin{array}{l}\text { Setiap CRC } \\
\text { terjadwal }\end{array}$ & $\begin{array}{l}\text { Kesesuaian } \\
\text { iadwal } \\
\text { produksi } \\
\end{array}$ & $\begin{array}{l}\text { Optimalkan } \\
\text { tonase CRC }\end{array}$ \\
\hline $\begin{array}{l}\text { Kelebihan } \\
\text { Persediaan }\end{array}$ & $\begin{array}{l}\text { Jumlah } \\
\text { dibanding } \\
\text { tonase CRC }\end{array}$ & 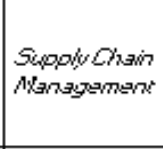 & $\begin{array}{l}\text { Kedatangan } \\
\text { dan } \\
\text { penyimpanan } \\
\text { CRC impor } \\
\text { dan lokal } \\
\end{array}$ & $\begin{array}{l}\text { CRC tonase } \\
\text { kecil }\end{array}$ & $\begin{array}{l}\text { Optimalkan } \\
\text { tonase CRC }\end{array}$ \\
\hline $\begin{array}{l}\text { Gerakan yang tidak } \\
\text { perlu }\end{array}$ & $\begin{array}{l}\text { Proses } \\
\text { Lhoovking }\end{array}$ & Operator & \begin{tabular}{|l|} 
Setiap hari \\
sejumlah $20-$ \\
30 CRC
\end{tabular} & $\begin{array}{l}\text { Kesesuaian } \\
\text { iadwal } \\
\text { produksi }\end{array}$ & $\begin{array}{l}\text { Optimalkan } \\
\text { tonase CRC }\end{array}$ \\
\hline $\begin{array}{l}\text { Cacat atau } \\
\text { Conaos }\end{array}$ & $\begin{array}{l}\text { Proses input } \\
\text { data }\end{array}$ & Operator & $\begin{array}{l}\text { Setiap bulan } \\
\text { ada } 2 \text { s.d } 3 \\
\text { kesalahan } \\
\text { input data }\end{array}$ & $\begin{array}{l}\text { Banyak data } \\
\text { CRC yang } \\
\text { harus diinput }\end{array}$ & $\begin{array}{l}\text { Optimalkan } \\
\text { tonase CRC }\end{array}$ \\
\hline
\end{tabular}

Dari tabel tersebut terungkap adanya penyebab utama pemborosan, yaitu kurang optimal tonase CRC yang saat ini adalah dalam kisaran 14 ton s.d 18 ton dikarenakan adanya keterbatasan kapasitas. Kemudian dibandingkan dengan potensi penghematan yang didapatkan jika tonase CRC dijadikan dalam kisaran 16 ton s.d 22 ton yang merupakan tren tonase masa datang. Selain data dari analisa 7 Waste juga dimasukkan data pemborosan pada proses rantai pasok, kemudian ditabelkan sebagai berikut:

Tabel 2. Total Potensi Penghematan

\begin{tabular}{|c|c|c|c|}
\hline $\begin{array}{c}\text { Faktor } \\
\text { Penyebab }\end{array}$ & $\begin{array}{l}7 \text { Waste in Lean } \\
\text { Thinking }\end{array}$ & Sumber & $\begin{array}{c}\text { Potensi } \\
\text { Penghematan } \\
\text { (USD /Bulan) }\end{array}$ \\
\hline \multirow{5}{*}{ Rantai Pasok } & $\begin{array}{l}\text { Transportasi yang } \\
\text { tidak perlu }\end{array}$ & $\begin{array}{l}\text { Transportasi CRC } \\
\text { Lokal }\end{array}$ & 5,000 \\
\hline & $\begin{array}{l}\text { Kelebihan } \\
\text { Persediaan }\end{array}$ & Sewa Gudang & 1,250 \\
\hline & $\begin{array}{l}\text { Transportasi yang } \\
\text { tidak perlu }\end{array}$ & $\begin{array}{l}\text { Transportasi CRC } \\
\text { Impor }\end{array}$ & 1,500 \\
\hline & Kelebihan Proses & Selisih tonase CRC & 2,000 \\
\hline & Menunggu & Kurang unit Trailer & 800 \\
\hline Operasional & $\begin{array}{l}\text { Total operasional } \\
7 \text { Waste }\end{array}$ & $\begin{array}{l}\text { Aktivitas dan } \\
\text { proses kerja }\end{array}$ & 23,000 \\
\hline \multicolumn{3}{|c|}{ TOTAL PENGHEMATAN PERBULAN } & 33,550 \\
\hline
\end{tabular}

\section{KESIMPULAN DAN SARAN}




\section{Kesimpulan}

Berdasarkan hasil pengolahan data pemborosan yang telah terjadi dan dijadikan sebagai potensi penghematan dimasa datang, maka dapat disimpulkan:

1. Pemborosan terjadi dikarenakan tidak optimalnya tonase CRC yang rendah karena disesuaikan dengan kapasitas mesin penunjang.

2. Investasi sebesar USD 900.000 akan mencapai Break Even Point setelah 26,83 bulan.

\section{Saran}

Saran - saran dari penulis adalah sebagai berikut :

- $\quad$ Ketersediaan suplai CRC dimasa datang akan menjadi krusial sehingga kapasitas mesin penunjang sudah seharusnya ditingkatkan.

- Perhitungan studi kelayakan bisnis atau investasi bisa digabungkan dengan potensi penghematan dari menghilangkan pemborosan yang telah terjadi.

\section{DAFTAR PUSTAKA}

Abdulmalek, F. A., \& Rajgopal, J. (2007). Analyzing the benefits of lean manufacturing and value stream mapping via simulation: A process sector case study. International Journal of production economics, 107(1), 223-236.

Dewi, S. K., \& Sartono, T. D. S. D. (2014). PENDEKATAN LEAN THINKING UNTUK PENGURANGAN WASTE PADA PROSES PRODUKSI PLASTIK PE. Research Report. IENACO.

Lambert, D. M., Cooper, M. C., \& Pagh, J. D. (1998). Supply chain management: implementation issues and research opportunities. The international journal of logistics management, 9(2), 1-20.

Verma, N., Raghuvanshi, B., \& Verma, T. (2015, November). Application of Lean Manufacturing-A Case Study on Jindal Steel Power Limited. In International Journal of Engineering Development and Research (Vol. 3, No. 4 (November 2015)). IJEDR.

Vlachos, I. Applying Lean Thinking to Reduce Uncertainty and Waste in Global Food Supply Chain. In: UNSPECIFIED Annual $15^{\text {th }}$ EURAM Conference, 17-20 Jun 2015, Warsaw, Poland. (In Press). 